\title{
REALISMO Y EPISTEMOLOGÍA EVOLUCIONISTA DE LOS MECANISMOS COGNITIVOS*
}

\author{
Antonio Diéguez \\ Departamento de Filosofía \\ Universidad de Málaga \\ dieguez@uma.es
}

RESUMEN: Los intentos de apoyar el realismo realizados desde la epistemología evolucionista no han conseguido ofrecer argumentos suficientemente poderosos, pese a su plausibilidad inicial. Aceptando que nuestras capacidades cognitivas existen porque aumentan nuestra eficacia biológica, no es en modo alguno evidente que aumenten nuestra eficacia biológica porque porporcionen un conocimiento verdadero sobre el mundo. La estrategia abductiva de inferencia que el realista emplea en relación con el éxito predictivo de la ciencia, es decir, el recurso a la verdad aproximada como mejor explicación de ese éxito, pierde mucha fuerza cuando se aplica al conocimiento ordinario.

PALABRAS CLAVE: epistemología evolucionista, realismo, capacidades cognitivas

SUMMARY: In spite of their initial plausibility, the arguments in favour of epistemic realism which evolutionary epistemology have offered are not powerful enough. Although we can assume that our cognitive abilities exist because they increase our fitness, it is by no means obvious that they increase our fitness because they provide true beliefs about the world. The realist's abductive estrategy of inference used in relation to scientific predictive success does not display the same strength when applied to ordinary knowledge.

KEY WORDS: evolutionary epistemology, epistemic realism, cognitive abilities

Según Hilary Putnam, la epistemología evolucionista, entendida como el intento de proporcionar una explicación darvinista de nuestras capacidades cognitivas, está irremediablemente comprometida con el realismo. La epistemología evolucionista concibe la razón como un producto de la evolución que proporciona al ser humano cierto beneficio para su supervivencia. ${ }^{1}$ Mas

* Agradezco a José María González Donoso, del Departamento de Ecología y Geología de la Universidad de Málaga, y a Julián Almaraz, del Departamento de Psicología Básica, sus útiles comentarios.

${ }^{1}$ Es habitual distinguir dos proyectos distintos, aunque a veces defendidos por los mismos autores, dentro de la epistemología evolucionista. El primero 
para dar contenido a esta afirmación ha de presuponer, según Putnam, que la razón es una capacidad para descubrir verdades, en el sentido realista de la verdad como correspondencia con los hechos. Éste es el problema principal que él señala en la epistemología evolucionista, a la que, dicho sea de paso, también acusa de mantener un "evolucionismo ultraoptimista", según el cual todo rasgo útil debe ser el producto de la selección natural. Como es bien sabido, Putnam ha sido uno de los críticos principales del realismo metafísico y, en especial, de la teoría de la verdad como correspondencia (cfr. Putnam 1983, pp. 230-233, y Putnam 1992, cap. 2).

En esta interpretación de las consecuencias que tendría la aplicación del darvinismo al conocimiento humano, Putnam no se separa demasiado de lo que había manifestado años antes Jacques Monod en El azar y la necesidad. Monod consideraba que la evolución había dotado al ser humano de capacidades para lograr una representación adecuada del mundo y para alcanzar predicciones exactas. La diferencia entre ambos está en que Monod asumía por completo la validez de esta aplicación del darvinismo a la epistemología (cfr. Monod 1970/1981, pp. 167168). Pueden citarse otros muchos nombres de autores que han sustentado posiciones epistemológicas realistas basándose en la

consistiría en utilizar la teoría de la evolución como una explicación aplicable analógicamente al cambio de teorías en la ciencia y, en general, al progreso de nuestros conocimientos. Michael Bradie ha llamado a este enfoque 'Programa de la evolución de las teorías' o, en siglas, EET; y Michael Ruse lo denomina 'Enfoque spenceriano' ( $c f r$. Bradie 1986 y Ruse 1990). Los representantes más conocidos serían Karl Popper, Donald Campbell, Konrad Lorenz, Stephen Toulmin, Nicholas Rescher y David Hull; y entre sus críticos están Michael Ruse, Richard Lewontin, Mario Bunge y Paul Thagard. El segundo proyecto, más propiamente científico, pretende comprender desde la aplicación literal de la teoría de la evolución las características de los mecanismos y capacidades cognitivas de los animales y del hombre. Bradie lo denomina 'Programa de la evolución de los mecanismos cognitivos' o EEM, y para Ruse es el 'Enfoque darvinista'. También se lo denomina, en ocasiones, 'bioepistemología'. Popper, Campbell, Lorenz y Hull estarían de nuevo entre sus representantes más conocidos, a los que habría que añadir a Rupert Riedl, Michael Ruse y Gerhard Vollmer, entre otros. En este trabajo nos ceñiremos a este último enfoque. Una comparación clarificadora entre ambos puede encontrarse en Vollmer 1987. 
aplicación de ideas evolucionistas. Karl Popper, Konrad Lorenz, Rupert Riedl, Donald Campbell, Gerhard Vollmer y C.A. Hooker serían probablemente los más repetidos.

Sin embargo, no todos los filósofos realistas ven con simpatía esta aplicación. Ilkka Niiniluoto, por ejemplo, estima que la aplicación literal de las teorías biológicas a la explicación del origen de nuestro conocimiento, y en especial al origen de la ciencia contemporánea, además de reducir la evolución cultural a la evolución biológica y representar, por tanto, un 'biologismo' que es cuestionable (por ejemplo, la sociobiología), conduce al instrumentalismo (el valor del conocimiento es medido por su utilidad para la supervivencia). Cree, en cambio, que la aplicación analógica (la EET de Bradie) no adolece de biologismo y es neutral con respecto al debate realismo-instrumentalismo ( $c f r$. Niiniluoto 1984, pp. 62-63).

Paradójicamente, un antirrealista como Richard Rorty se manifiesta en el mismo sentido que Niiniluoto y en sentido contrario a Monod y a Putnam. En Truth and Progress, escribe Rorty:

$\mathrm{Si}$, como buenos darvinistas, queremos introducir tan pocas discontinuidades como sea posible en la historia de cómo llegamos desde los monos hasta la Ilustración, debemos rechazar la idea de que la Naturaleza ha establecido una sola función entrada-salida que, encarnada en cada miembro de nuestra especie, nos capacita para representar nuestro entorno con exactitud. Pues esta idea requiere que la Naturaleza misma haya dividido el torbellino causal que rodea a estos organismos en entradas discretas y que haya adoptado una función entrada-salida particular como distintivamente suya [...]. (Rorty 1998, p. 40)

Y para acabar de complicar las cosas, cabe también declarar absurda desde una perspectiva evolucionista tanto la pretensión realista de la existencia de una realidad independiente, como la pretensión antirrealista de que lo que llamamos 'realidad' es algo construido socialmente o de algún otro modo ( $c f r$. Castrodeza 1998 y 1999 , pp. 56-62). ${ }^{2}$

${ }^{2}$ Castrodeza sostiene que la realidad sería solo el producto del solapamien- 
Uno de los principales obstáculos en el buen discurrir de este debate es la diversidad de opiniones existentes acerca de lo que hay que entender por realismo. Así, en una misma recopilación de trabajos, encontramos que Michael Ruse utiliza el hecho de la evolución para rechazar el realismo, entendiendo por realismo algo que incluye la creencia en la cognoscibilidad de la cosa-en-sí y la teoría de la verdad como correspondencia (aunque acepta un cierto realismo de sentido común, que él identifica con el realismo interno de Putnam), y que inmediatamente después Robert G. Meyers asume como una consecuencia ineludible de la evolución, la existencia de una realidad estructurada e independiente de la mente que la conoce. De modo que la impresión inicial es que ambos parecen estar manteniendo posturas encontradas; y, sin embargo, el contenido de sus trabajos muestra más bien que los desacuerdos no son tan radicales. Pese a sus reticencias metafísicas, Ruse está asumiendo un realismo ontológico en el que la realidad no posee una estructura intrínseca, mientras que Meyers está asumiendo que sí la tiene. Ninguno de los dos va más allá (cfr. Ruse 1990 y Meyers 1990). Sería pues deseable un mayor consenso sobre el significado del término 'realismo' que evitara que los desacuerdos se agrandaran sin necesidad.

No pretendo que este trabajo consiga despertar dicho consenso, pero al menos a efectos de delimitar con claridad en qué medida cabe o no cabe sustentar el realismo sobre la epistemología evolucionista, resulta ineludible especificar de antemano de qué tipo de realismo se está hablando, aun a riesgo de que dicha caracterización no recoja ciertos matices o variantes.

\section{Caracterización del realismo}

Entenderé aquí que el realismo consiste en la afirmación de las siguientes tesis:

(1) Existe un mundo que, al menos en algunas de sus características, es ontológicamente independiente de cualquier

to de los diversos fenotipos ampliados (en terminología de Richard Dawkins), es decir, de los distintos efectos de los genes sobre el mundo. 
acto de conocimiento o de cualquier conceptualización. Dicho de otro modo, no es por completo el producto de un proceso de conocimiento. En particular, su mera existencia no depende de la existencia de sujetos cognoscentes.

(2) Ese mundo independiente es cognoscible en muchos aspectos de forma adecuada, aunque perfectible y parcial; incluso en aquellos aspectos que no son observables. Tal conocimiento lo es de dicho mundo, y no - o no exclusivamente - de algo que el sujeto cognoscente ponga en él. Así pues, podemos alcanzar ciertas verdades sobre el mundo.

(3) Nuestras teorías sobre el mundo serán verdaderas o falsas en función de su correspondencia o falta de correspondencia con la realidad independiente.

A la tesis (1) suele designársela como realismo ontológico, a la tesis (2) como realismo epistemológico, y a la tesis (3) como realismo semántico. Cabría hacer distinciones más precisas en lo que se refiere a dichas tesis. En otro lugar he argumentado que, cuando se aplica a la ciencia, el realismo ha de ser reformulado de un modo más detallado para poder recoger las propuestas realizadas por sus defensores ( $c f r$. Diéguez 1998, cap. 3); sin embargo, creo que para nuestros propósitos esta caracterización es suficiente. Es importante hacer notar en este momento que el tipo de conocimiento al que se refieren las tesis anteriores es el que podemos alcanzar todos los seres humanos en nuestra vida cotidiana, y no únicamente algunos seres humanos tras una larga formación y con ayuda de un sofisticado instrumental. Dicho de otro modo, no se trata aquí de un realismo sobre el conocimiento científico, sino de un realismo sobre el conocimiento ordinario. Por ese motivo dejo de lado, entre otras cosas, la tesis del realismo convergente, o, mejor sería decir, del realismo sobre el progreso, según la cual nuestro conocimiento científico contiene cada vez más verdades y/o menos falsedades. ${ }^{3}$

${ }^{3}$ Un problema adicional para la epistemología evolucionista en el que aquí no entraremos es si se puede pasar de la explicación evolucionista de nuestro conocimiento cotidiano a una explicación evolucionista del conocimiento 
Debemos tener en cuenta también que el realismo tiene modalidades más fuertes y otras más débiles. Así, puede haber quien acepte la tesis (1) pero rechace las demás; un ejemplo podría ser el idealismo trascendental de Kant, el realismo interno de Putnam o el realismo de sentido común de Ruse. ${ }^{4}$ Puede haber también quien acepte las tesis (1) y (2) pero rechace la (3), como puede ser el caso entre los pragmatistas y los coherentistas. Otras combinaciones o bien son incoherentes (aceptar (2) y rechazar (1)) o bien son demasiado extravagantes (aceptar (3) y rechazar (2) es tanto como declararse escéptico). Y queda, evidentemente, la posibilidad de aceptarlas todas, como haría un realista fuerte; de rechazarlas todas, como haría un idealista subjetivo, un solipsista o un fenomenista extremo; o de declararlas sin sentido, como haría un positivista, o como parece hacer Rorty en ocasiones.

científico. Esta segunda explicación es más discutible, ya que el conocimiento científico se desarrolla habitualmente en unas circunstancias muy alejadas de las que constituyeron el entorno natural en el que evolucionaron las capacidades cognitivas humanas. No obstante, puede argüirse que dicho conocimiento es un producto reciente y derivado de esas capacidades cognitivas que fueron seleccionadas por el valor adaptativo del conocimiento cotidiano que proporcionaban ( $c f r$. Vollmer 1987, Ruse 1986, cap. 5, Goldman 1990, y para una crítica de este razonamiento, Bradie 1990). Donald Campbell, sin embargo, se niega a extender la explicación evolucionista (en el sentido EEM) al conocimiento científico ( $c f r$. Callebaut 1993, p. 295). Creo que en este asunto conviene no ser demasiado ambiciosos. Lo que podemos afirmar con bastante seguridad es, como señala Steven Pinker, que "tenemos nuestras mentes porque su diseño conseguía resultados cuyos beneficios superaban los costos en las vidas de los primates africanos del Plio- pleistoceno" (Pinker 1997, p. 155). Pero no podemos pasar de ahí a consderar la capacidad de hacer ciencia como si cumpliera una función adaptativa. Muy bien pudiera ser, como el pulgar del panda o las suturas craneales en el hombre, una exaptación en el sentido de Gould y Vrba ( $c f r$. Pinker 1997, p. 301). En consecuencia, aunque se admitiera que la epistemología evolucionista apoya sin ambages un realismo acerca del conocimiento ordinario, se estaría todavía lejos de aportar con ello un argumento sólido en favor del realismo científico.

${ }^{4}$ Nótese que la independencia del mundo de la que habla la tesis (1) no implica la aceptación del carácter nouménico de dicho mundo, tal como explicaremos después. Un realista ontológico puede considerar, siguiendo a Putnam, que la distinción kantiana entre fenómeno y noúmeno perjudica la comprensión de nuestro conocimiento en lugar de aclararla. 


\section{El realismo semántico}

¿Qué se puede decir desde la epistemología evolucionista de los mecanismos cognitivos acerca de estas tres tesis? Para empezar por el final, es importante reconocer que la tesis (3) no siempre ha sido cuidadosamente distinguida de la tesis (2). En ocasiones se ha defendido el realismo semántico como si formara un todo con el realismo epistemológico. Y no es así desde el punto de vista conceptual, como acabamos de decir. Aceptar la posibilidad de obtener conocimiento adecuado o incluso verdadero sobre el mundo no compromete necesariamente con la tesis de que la verdad consiste en una correspondencia entre los enunciados y el mundo. El realismo epistemológico deja abierto todavía el concepto que haya de asumirse acerca de la verdad.

El realismo semántico, según lo estamos entendiendo aquí, consiste en asumir la teoría de la verdad como correspondencia. No parece en principio que de la evolución de nuestras capacidades cognitivas se pueda sacar alguna conclusión inmediata acerca de si dicha teoría supera o no en algún aspecto a sus rivales: la teoría de la verdad como coherencia, la teoría pragmatista de la verdad, la teoría de la verdad como desentrecomillado, etc. El realismo epistemológico de carácter evolucionista tiene sentido tanto si se entiende acompañado del realismo semántico como si no. En efecto, podemos sostener que el mundo es cognoscible precisamente porque nuestras capacidades cognitivas son el resultado de la adaptación a dicho mundo, y a continuación defender la idea de que se da una correspondencia de muchas de nuestras creencias con los hechos, como hace C.A. Hooker (1987, pp. 273-279, y 1995, pp. 16-17). Pero también podemos sostener lo primero y rechazar lo segundo, como hace por ejemplo Michael Ruse (1986, cap. 5), quien siguiendo a Putnam considera que la idea de una correspondencia de nuestros enunciados con una realidad independiente está plagada de dificultades conceptuales. No es de extrañar esta disparidad de opiniones si reparamos en que la verdad no es una noción que, por el momento, haya podido ser naturalizada, aunque haya habido intentos muy sugerentes en tal sentido ( $c f r$. Millikan 1984). 
Ahora bien, es bastante comprensible que los intentos de apoyar el realismo epistemológico en el hecho evolutivo hayan ido acompañados frecuentemente - y esto es lo que disgustaba a Putnam - del realismo semántico. Si estamos dispuestos a aceptar que el mundo es cognoscible debido precisamente a nuestra adaptación a él, parece entonces razonable esperar la correspondencia de muchas de nuestras creencias con los hechos, ya que esa correspondencia permitiría explicar, o al menos eso es lo que defiende el realista, un incremento en nuestras posibilidades de superviviencia y reproducción. Sin esa correspondencia, el realismo epistemológico, aunque siguiera siendo inteligible, perdería en gran medida su posible apoyo evolucionista, lo cual explica las reticencias de Michel Ruse al respecto, sobre las que ahora volveremos.

Pasemos ahora a analizar las tesis (1) y (2), que son las que más discusión han generado en este ámbito.

\section{El realismo ontológico}

El realismo ontológico es la afirmación principal que hay detrás del realismo hipotético asumido desde bases evolucionistas por Konrad Lorenz (1973) y Donald Campbell (1974), entre otros (cfr. Skagestad 1981). La defensa del realismo ontológico vendría a decir más o menos lo siguiente: aceptar el hecho evolutivo de la adaptación, en este caso de la adaptación de nuestras capacidades cognitivas, exige reconocer un medio externo al que ha de adaptarse el organismo. El mundo no puede ser un producto de nuestras capacidades cognitivas, puesto que éstas han surgido como resultado de una adaptación al mundo. En palabras de A.J. Clark, la afirmación de que

el universo físico existe independientemente de nuestro conocimiento de él es una condición necesaria para tener siquiera una explicación evolucionista. Pues concebir la mente como el producto de un proceso de supervivencia y reproducción diferencial es, evidentemente, colocar el universo físico antes que la mente en el orden ontológico. (Clark 1984, p. 484) 
Podría añadirse incluso que para que haya sido posible la evolución, ese mundo real e independiente ha de poseer un orden previo (cfr. Meyers 1990 y Niiniluoto 1999, p. 87). Por lo tanto, si se acepta esta precisión, la evolución de los seres vivos y, en particular de los seres humanos, presupone la existencia de una realidad independiente y estructurada en cierto grado.

Campbell califica este realismo de hipotético porque la existencia de la realidad independiente se presupone, no se justifica. Simplemente sin ella carecería de sentido la mera posibilidad de la evolución biológica y de su estudio; no podríamos hablar, como de hecho hace el naturalista, de la relación entre las capacidades cognitivas de un animal y el medio ambiente que éste trata de conocer.

La dificultad en este argumento surge a la hora de aclarar qué se entiende por una realidad independiente. Si lo que se quiere decir es que la existencia del mundo no está causada por la mente humana, es decir, que hay un sustrato real que la mente humana no crea por el mero hecho de intentar conocerlo y que persistiría del mismo modo en su existencia en caso de que no hubiera ninguna mente humana, pocos antirrealistas actuales negarían esto. La negación de esta tesis conduce al solipsismo o al idealismo, posturas que no son las que suele asumir el antirrealismo contemporáneo. Ni siquiera el constructivismo social, pese a su retórica oscilante en este punto, denunciada repetidamente por sus críticos, niega clara y definitivamente tal $\operatorname{cosa}^{5}$ Es más, la realidad del mundo exterior no era algo mera-

${ }^{5}$ Los promotores del Programa Fuerte en sociología de la ciencia, Barry Barnes y David Bloor, han declarado expresamente que no pretenden negar la existencia de un mundo externo, y en un sentido similar se ha expresado Karin Knorr-Cetina. Por otra parte, el rechazo de algunos constructivistas sociales, como Harry Collins, a explicar las decisiones de los científicos, especialmente el cierre de las controversias, apelando a que el mundo es realmente de una determinada manera, la cual queda manifiesta, debe entenderse como una actitud metodológica y no como una tesis ontológica que niegue la existencia de una realidad independiente ( $c f r$. Niiniluoto 1999, cap. 9). En lo que respecta a las tesis de Bruno Latour y Steve Woolgar en su obra Laboratory Life, lo que según estos autores resulta construido socialmente en los laboratorios no es la realidad sin más, sino lo que cuenta como realidad para la ciencia, es decir, los hechos científicos. Pero no se excluye la existencia de hechos no científicos no 
mente hipotético para el idealismo trascendental de Kant, sino un hecho totalmente seguro. ${ }^{6}$ En este punto Kant habría sido, pues, más realista que los defensores del realismo hipotético.

Aclaremos que el realismo ontológico sustentado en la epistemología evolucionista no tiene por qué identificarse - aunque algunos realistas lo hagan - con la postulación de una realidad nouménica y, por tanto, permanentemente inaccesible; ni tampoco con la postulación de un mundo prefabricado, como el que Putnam rechaza. Las objeciones de Michael Ruse son, en este punto, poderosas. Para la explicación evolucionista de nuestras capacidades cognitivas basta con la afirmación de que éstas son el producto de un mundo al que ellas mismas pertenecen y cuya existencia no puede obviamente depender de la existencia de tales capacidades. Pero esto no tiene por qué llevar a concebir nuestras capacidades cognitivas como algo meramente pasivo frente a un mundo exterior. La relación constitutiva entre el mundo y la mente puede tener una doble dirección, tal como señala Putnam. Dicho de otro modo, no es necesario suponer que el mundo lleva las etiquetas puestas o que está compuesto por objetos autoidentificantes. Más bien hay razones para pensar que nuestros esquemas conceptuales tienen un papel crucial en la determinación de la estructura final de la realidad; y estos esquemas conceptuales son constructos humanos. La existencia independiente del mundo de la que habla el realista ontológico no exige también una independencia conceptual del mundo. En

construidos, por tanto, en laboratorios. No obstante, es cierto que Woolgar, en obras más tardías, se ha expresado en términos decididamente idealistas (cfr. Woolgar 1988). Entre los antirrealistas contemporáneos que más se han acercado al idealismo, un caso notorio es el de Nelson Goodman, pero, al igual que sucede con Derrida, su filosofía da cabida a interpretaciones compatibles con el realismo ontológico.

${ }^{6}$ Cfr. Lütterfelds 1999. Sobre este asunto insiste también Julián Pacho, centrando en él la diferencia fundamental entre el realismo crítico kantiano y el realismo hipotético. Pacho señala que el realismo hipotético estaría en esto más cerca de Hume que de Kant (cfr. Pacho 1995, pp. 82-83). En efecto, en el prólogo de la segunda edición de la Critica de la razón pura, Kant escribe: "Soy consciente de una forma tan segura de que hay cosas fuera de mí que se relacionan con mi sentido como lo soy de que existo determinado por el tiempo" (Kant 1787/1966 BXLI). 
tal sentido, el realismo podría ser compatible con cierta relatividad de la estructura ontológica del mundo con respecto a nuestros sistemas conceptuales, sin caer por ello en el idealismo conceptual y sin renunciar, como quiere Ruse, al realismo epistemológico en el sentido en que lo hemos definido ( $c f r$. Niiniluoto 1999, pp. 218-226).

Habría que concluir entonces que la epistemología evolucionista apoya un realismo ontológico básico, pero que éste es poco interesante desde el punto de vista del debate actual acerca del realismo. Se trataría de una tesis aceptable para instrumentalistas, neopragmatistas moderados, realistas internos, empiristas constructivos, relativistas, e incluso idealistas trascendentales y constructivistas sociales. En suma, algo que con uno que otro matiz aclaratorio en lo que respecta al alcance del término 'independiente' es compatible con casi todas las formas recientes del antirrealismo.

$\mathrm{Si}$, en cambio, lo que se quiere decir con 'realidad independiente' es que la adaptación de un organismo a su entorno exige la independencia causal del entorno con respecto al organismo, entonces la afirmación se vuelve cuando menos controvertida. El entorno puede ser considerado, en cierta medida, como un producto de esos mismos organismos (cfr. Lewontin 1982), e incluso de sus genes ( $c f r$. Dawkins 1999). Lewontin afirma taxativamente que los organismos, más que adaptarse a su entorno, lo crean. Por eso cree que "el error fundamental de las epistemologías evolucionistas tal como son ahora es su fracaso a la hora de reconocer cuánto de lo que hay 'ahí fuera' es el producto de lo que hay "aquí dentro" " (Lewontin 1982, p. 169). No obstante, hay que aclarar que el rechazo de esta segunda interpretación (y así lo reconoce finalmente Lewontin) no socava la primera. El entorno (Umwelt) puede ser dependiente de los organismos o las especies al tiempo que el mundo (Welt) es independiente de éstos en su existencia. Si "un entorno es naturaleza organizada por un organismo" a partir de "trozos y piezas del mundo" (Lewontin 1982, p. 160), es porque existe un mundo exterior del que proceden las piezas y los trozos. Las observaciones de Lewontin no irían tanto contra el realismo ontológico como con- 
tra una concepción pasiva de la relación entre el organismo y el entorno. En ello estaría cerca, por tanto, del realismo interno de Putnam.

\section{El realismo epistemológico}

En lo que respecta al realismo epistemológico, es obvio que su defensa es más comprometida que la de la tesis anterior y, en consecuencia, hay epistemólogos evolucionistas que aceptan el realismo ontológico pero rechazan el epistemológico ( $c f r$. Clark 1984, Ruse 1990, Stein 1990). No obstante, es una tesis más interesante y, si puede ser defendida plausiblemente, aportaría más al debate sobre el realismo. El argumento en su favor diría más o menos lo siguiente:

(I) Nuestras capacidades cognitivas son un rasgo adaptativo producto de la selección natural. La suposición alternativa de que no son resultado de la selección natural o de que son sólo un subproducto de la evolución choca con una gran parte de la evidencia paleoantropológica; en especial, con la evidencia de la relación entre el aumento del tamaño cerebral en los humanos en proporción a su tamaño corporal (sobre todo a partir del Homo habilis), el enriquecimiento de la dieta (incremento del consumo de carne), el avance en el uso y la fabricación de instrumentos, y el aumento en la complejidad de los grupos sociales (cfr. Mithen 1996, caps. 6 y 11, y Boyd y Silk 2000, cap. 9; y para una crítica de esta tesis puede leerse Martin 2000).

(II) En tanto que rasgos adaptativos, las capacidades cognitivas han sido seleccionadas porque aumentan la eficacia biológica, es decir, porque favorecen la supervivencia y el éxito reproductivo de los individuos mejor dotados de ellas.

(III) Dado que la función de estas capacidades es conocer el entorno, su adaptación consistirá en proporcionar un conocimiento que sea lo suficientemente adecuado como para haber favorecido la eficacia biológica. La supervivencia habría sido enormemente dificultada si nuestras capacidades 
cognitivas no fueran fiables en cuanto al conocimiento que proporcionan sobre el entorno.

(IV) Por lo tanto, podemos conocer de forma adecuada el mundo exterior. Lo cual significa que nuestras creencias sobre él han de ser aproximadamente verdaderas en muchos casos.

La cita clásica que se suele aducir como soporte de este argumento procede de Quine y dice así: "Las criaturas que yerran inveteradamente en sus inducciones tienen la tendencia patética, pero encomiable, a morir antes de reproducir su clase" (Quine 1969/1997, p. 66). También Popper defendió esta idea. En una de sus últimas obras escribe lo siguiente: "A pesar de su incertidumbre, de su carácter hipotético, gran parte de nuestro conocimiento será objetivamente verdadero: corresponderá a hechos objetivos. De otro modo difícilmente habríamos sobrevivido como especie" (Popper 1990, p. 32). El supuesto contenido en el argumento es que las creencias verdaderas sobre el mundo tienen por lo general un mayor valor adaptativo que las falsas, ya que, entre otras cosas, permiten anticipar mejor el comportamiento del medio y, por tanto, también modificarlo con más eficiencia.

La posesión de órganos sensoriales fiables es un rasgo particularmente subrayado en relación con este argumento. El ojo ha sido desarrollado de forma independiente pero con una estructura similar por muy diversos grupos animales. La información que proporciona es selectiva y falible, como lo muestran las ilusiones ópticas, pero en general es una información fiable y correcta dentro de sus límites, y su evolución manifiesta un refinamiento en la recepción de dicha información.

Pero no haría falta restringirse al conocimiento acerca del mundo natural para ir en defensa del realismo epistemológico. Si damos por buena la hipótesis que sostiene que la inteligencia evolucionó sobre todo para resolver problemas sociales, otro ejemplo que podría servir para los propósitos del realista lo proporcionaría la adaptación de nuestra mente al entorno social. Tal como argumenta Denise D. Cummins (2000), el éxito 
reproductivo de un individuo está ligado en muchas especies (incluidas las de los primates) a la maximización del rango dentro del grupo social. Esto implica, además de tener el tamaño y la fuerza adecuados, desarrollar estrategias cognitivas para reconocer las relaciones de dominio, aprender rápidamente las normas sociales, detectar las violaciones de dichas normas, hacerse una representación de las obligaciones recíprocas y leer las intenciones de los otros. El realista podría apoyarse en esto para decir que la maximización del éxito reproductivo depende de la capacidad para conocer correctamente una serie de hechos objetivos acerca del entorno social. Sin una representación verdadera de las relaciones sociales que imperan en el grupo, sencillamente se disminuyen drásticamente las oportunidades de reproducirse.

Un corolario de estos argumentos, en el que no entraremos, es que el realismo epistemológico no se debería aplicar sólo al conocimiento generado por nuestra especie, sino que habría de extenderse a otras especies animales con capacidades cognitivas desarrolladas evolutivamente. Podría decirse que ciertos animales poseen representaciones mentales adecuadas de su entorno, aunque, al igual que las de los seres humanos, esto sea siempre dentro de unos límites impuestos por las características de sus sistemas sensoriales y neurológicos. Así, por ejemplo, un pollo puede reconocer objetos que están parcialmente ocultos y hay fuertes indicios de que un chimpancé puede reconocer su imagen en un espejo ( $c f r$. Rogers 1997).

También aquí conviene hacer ciertas precisiones. El realismo epistemológico que podría defenderse desde el evolucionismo no es un realismo ingenuo. Asume que nuestras capacidades cognitivas son selectivas e imperfectas y que, por lo tanto, la información que procesan no es un reflejo de todos los aspectos del mundo real. Una foto impresa en un periódico, según la comparación que hace Lorenz, está formada por una trama de puntos que no están en el objeto real, y que sólo permite recoger algunos aspectos de éste. No obstante, no hay ningún punto en esa trama que no responda a algo del objeto real, y, por otra parte, una trama más fina puede mejorar la imagen recogiendo aspectos que la trama más gruesa no permitía recoger. En con- 
junto, pues, la imagen formada mediante puntos es una imagen adecuada del objeto ( $c f r$. Lorenz 1941/1982). Esto significa que el realista epistemológico evolucionista no espera más que una adecuación parcial y aproximada entre nuestro conocimiento y el mundo. Al fin y al cabo, las capacidades cognitivas habrían sido seleccionadas por aumentar la eficacia biológica, esto es, por ser suficientemente buenas para resolver problemas de supervivencia y reproducción dada la historia filogenética de ciertas especies, no por su valor intrínseco.

Son injustas, pues, las críticas contra el realismo que se limitan a señalar que la percepción es selectiva, ambigua y simplificadora, que hay aspectos de la realidad que pueden ser conocidos por unas especies y no por otras, o que no pueden ser conocidos en absoluto. ${ }^{7}$ El que sean concebibles capacidades cognitivas más amplias y mejores que las que de hecho tenemos - y de las cuales carecemos debido quizás a imposiciones filéticas y construccionales o a diversos condicionamientos evolutivos (pleiotropía, heterosis, etc.) - no impide que las que poseemos tengan la suficiente fiabilidad. El realista no necesita, por tanto, exigir (pace Stich) que tales capacidades sean "óptimas o estén

${ }^{7}$ Sjölander (1997), por ejemplo, argumenta que una epistemología constructivista podría explicar mejor que una realista ciertas características de los sistemas cognitivos de las serpientes y de otros animales inferiores. Algunas investigaciones parecen mostrar que las serpientes no viven en un mundo único, sino en varios mundos diferentes, y la epistemología constructivista mantiene que no hay una única realidad, sino muchas, producto todas ellas de los diferentes sistemas cognitivos. Sin embargo, el realismo puede encajar también los datos de la etología y de la neurofisiología sin tener además que postular realidades múltiples. Para el realismo, sistemas cognitivos diferentes dan lugar a diferentes resultados perceptivos debido a que seleccionan aspectos diferentes de una misma realidad, no porque creen diversas realidades. En el caso de las serpientes, el hecho de que no puedan integrar la información en una representación centralizada, no significa que la realidad "esté en la mente", o que no haya objetos independientes con características propias. Para el realista significa sólo que las serpientes no pueden ver la realidad de ese modo. Sjölander parece suponer — erróneamente- que sólo cabría hablar de una realidad independiente si no hubiera más que un modo de acceder a ella, un modo que proporcionaría la visión más verdadera de la realidad. Puesto que no existe ese modo único de acceso, concluye entonces que hay diferentes realidades construidas. 
muy cerca de lo óptimo en la tarea de aumentar la eficacia biológica" (Stich 1990, p. 57); sólo necesita exigir que la aumenten lo suficiente.

Las réplicas de los críticos no suelen poner en duda las premisas (I) y (II) del argumento realista. Respecto a la premisa (II), es lógico que sea así, pues constituye un elemento central de la teoría de la evolución. La premisa (I), sin embargo, no tiene ese carácter. Quizás sea su amplia aceptación entre los científicos lo que explica que no haya sido rechazada casi nunca por los filósofos, aunque hay excepciones, como Thomas Nagel (1986, cap. 4) y Stephen Stich (1990, cap. 3) (para una discusión, véase Stein 1996, cap. 6). Sea como sea, las réplicas al argumento realista se han centrado en negar que sea necesario calificar de (aproximadamente) verdadero un conocimiento por el hecho de ser el producto de unas capacidades seleccionadas por su valor adaptativo.

\section{5. ¿Es la verdad más adaptativa que la falsedad?}

En efecto, una objeción repetida contra el argumento realista es que las creencias verdaderas no tienen por qué tener mayor valor adaptativo que las falsas. Hay creencias falsas que son muy útiles para la supervivencia y podrían aumentar la eficacia biológica del que las tuviera. David S. Wilson presenta el siguiente caso: la consideración del enemigo como un ser infrahumano motiva más en la lucha que la idea de que es igual a nosotros en su naturaleza. De modo que si dicha creencia viniera dada por una mutación genética, sus portadores dejarían más descendencia ( $c f r$. Wilson 1990, p. 39). Muchas creencias compartidas socialmente pueden estimarse de este mismo modo: tendrían un valor adaptativo, en la medida en que contribuyen a la supervivencia de los individuos pertenecientes al grupo social que las sustentan y, sin embargo, serían falsas.

Otro ejemplo en contra del realismo epistemológico lo ofrece la psicología del asco ( $c f r$. Stich 1994, pp. 36-37, y Pinker 1997, pp. 180-182). El asco nos hace evitar alimentos sanos cuya apariencia es similar a la de sustancias perjudiciales para la salud. Incluso nos hace rechazar alimentos que han estado en 
contacto con cosas que encontramos repugnantes pero que no representan ningún peligro. Para una especie omnívora como la nuestra, el asco puede ser una adaptación para evitar alimentos dañinos, si bien nos lleva también erróneamente a evitar alimentos nutritivos. El asco puede inducirnos a creencias falsas sobre el resultado de comer determinadas sustancias que en realidad son nutritivas, pero en otras ocasiones puede salvarnos la vida. Tal como dice Stephen Stich:

Cuando se trata de envenenamiento en los alimentos, la selección natural puede muy bien preferir una estrategia inferencial extremadamente cauta y que a menudo resulte falsa a una estrategia menos cauta pero que permita obtener con más frecuencia la respuesta correcta (Stich 1994, p. 347, cfr. Stich 1990, pp. 61-62).

Encontramos un caso similar en ciertos tipos de mimetismo, cuando una especie no venenosa para sus depredadores imita los colores de otra que sí lo es o que les resulta indigesta, y de este modo evita el ataque. Los depredadores tendrán una representación falsa del mundo, al tomar individuos no venenosos por venenosos; pero, a pesar de ello, evitar esos colores incrementa su eficacia biológica.

Todo esto muestra, según los críticos del realismo epistemológico, que nuestras capacidades cognitivas no están adaptadas para proporcionar creencias verdaderas, sino creencias suficientes para la supervivencia y la reproducción. La selección natural nos prepara para dejar descendientes, no para hallar verdades. Y para eso puede bastar con creencias falsas pero útiles.

Una objeción que también se repite a menudo es la de la circularidad del argumento realista. En realidad, la acusación de circularidad se suele dirigir a la epistemología naturalizada en su conjunto, pero hay una versión que atañe específicamente al realismo. Para defender el realismo desde la teoría de la evolución - se dice-, hay que hacer antes una interpretación realista de dicha teoría. Esta acusación no parece, sin embargo, que haga demasiada justicia al realista. Éste toma de la teoría de la evolución la premisa de que nuestras capacidades cognitivas son el 
producto de la evolución y que nos proporcionan una adaptación al medio. Una interpretación antirrealista de la teoría de la evolución no puede rechazar esto sólo por ser antirrealista. El realista no está tomando, pues, de la teoría de la evolución nada distinto de lo que tomaría el antirrealista.

Un defensor del realismo como Alan Goldman admite que la selección natural de nuestras capacidades cognitivas no prueba que nuestras creencias sobre el mundo sean verdaderas; considera, empero, que hay casos en los que sí deben serlo: cuando la información es necesaria para evitar peligros o para la obtención de alimento. Pero en tales casos - reconoce - se trata de verdades limitadas al ámbito de lo observable. Es sólo este tipo de casos el que permitiría afirmar que dichas capacidades han sido seleccionadas por su tendencia a producir creencias verdaderas ( $c f r$. Goldman 1990, pp. 41 y 43). El realista no afirmaría, pues, que la verdad sea siempre más adaptativa que la falsedad. Se limitaría a reconocer que, cuando lo que está en juego es la supervivencia y la reproducción, los errores se pagan y son eliminados, por lo que los mecanismos cognitivos que tienden a producir creencias verdaderas en tales contextos resultan seleccionados. Eso no excluye que, sobre asuntos no vitales, los errores puedan tener a veces su utilidad ( $c f r$. Pacho 1995, cap. 15). No obstante, el crítico también cuestiona que las creencias falsas no puedan mejorar la eficacia biológica del organismo ni siquiera en estos casos extremos donde se juega la vida o la muerte. El ejemplo de Wilson antes citado así lo manifiesta.

El realista podría en principio admitir las excepciones ocasionales. La cuestión, para él, no es si creencias falsas pueden tener valor adaptativo (que probablemente pueden). La cuestión es si gracias a la selección natural disponemos de capacidades cognitivas que, aunque susceptibles de error, generan un conocimiento verdadero en una proporción suficientemente alta. No es, por tanto, cierto que el realista "asum[a] ingenuamente que para los humanos el único modo de comportamiento adaptativo en su medio ambiente [sea] poseer representaciones mentales que correspondan directamente con lo que está 'realmente ahí fuera" (Wilson 1990, p. 56). El realista podría aceptar que 
en ocasiones aisladas y afortunadas "es adaptativo distorsionar las propiedades y relaciones entre las entidades que existen, o inventar entidades completamente nuevas que no tengan contrapartida en la realidad" (Wilson 1990, p. 56).

No obstante, este tipo de respuesta encierra el peligro de vaciar de contenido la tesis realista. Si se admite que puede haber creencias falsas con valor adaptativo, pero se insiste en que son excepciones, el realista está obligado entonces a concretar en qué circunstancias es de esperar que no se produzcan tales excepciones. ${ }^{8}$ Una posibilidad que cabe aventurar, trasladando a esta discusión lo que algunos realistas han aducido en el debate sobre el realismo científico, es que tal cosa sucede cuando es necesaria una predicción reiterada y con cierto grado de exactitud. Es entonces cuando disponer de unos sentidos fiables y unas creencias verdaderas parece claramente una ventaja adaptativa. Con conocimientos falsos es muy improbable que puedan realizarse de forma continuada predicciones adecuadas en situaciones variables o sobre fenómenos muy diversos.

Los ejemplos que se citan en contra del realismo epistemológico con base evolucionista suelen ser ejemplos de creencias falsas (supersticiones, creencias racistas, etc.), o de creencias sólo parcialmente verdaderas o confusas (la sustancia $A$ y la sustancia $B$ son venenosas, cuando en realidad sólo lo es $A$ ) que pueden, sin embargo, motivar acciones más adaptativas que las correspondientes creencias verdaderas. Pero el realista dirá que no hay por qué generalizar este tipo de situaciones. Cuando lo que se requiere para la supervivencia no son acciones fuertemente motivadas, sino acciones con resultados muy precisos, la verdad de las creencias a partir de las cuales puede realizarse una predicción de los resultados posibles se vuelve de suma importancia, al menos en una serie continuada y variada de tales acciones.

Un ejemplo de este tipo de acciones precisas con valor adaptativo que exigen una gran capacidad predictiva y de planificación, y que difícilmente podrían realizarse con éxito sin una

${ }^{8}$ Como dice Stich, está obligado a señalar "qué clase de verdades y de errores son importantes" (Stich 1990, p. 162, nota 7). 
representación básicamente correcta del entorno, podría ser el de los movimientos balísticos, como arrojar una piedra o una lanza, o clavar un clavo. El neurofisiólogo William H. Calvin ha especulado incluso con la posibilidad de que, dado que las zonas de la corteza cerebral que intervienen en la audición del lenguaje hablado controlan también los movimientos de la mano y la boca, estos movimientos balísticos hayan desempeñado un papel fundamental en el desarrollo de la inteligencia humana (cfr. Calvin 1996, cap. 6). Otro ejemplo posible es el de la localización y obtención de alimento. Para llevar a cabo esa tarea es necesario disponer de la capacidad para formar mapas cognitivos complejos y para almacenar en la memoria información correcta acerca de dónde se encuentra el alimento y qué momento es el oportuno para obtenerlo ( $c f r$. McLean 2001).

No obstante, el realista tampoco consigue aquí una ventaja definitiva. No puede establecerse una conexión necesaria entre la verdad de nuestras creencias y el éxito predictivo de las mismas (cfr. Laudan 1996). Con la teoría ptolemaica podían hacerse predicciones muy precisas sobre el movimiento de los planetas, aun cuando era una representación falsa del universo. En el ámbito del debate sobre el realismo científico, algunos realistas han intentado superar esta falta de conexión mediante una inferencia de la mejor explicación. Aunque no haya conexión necesaria entre la verdad de una teoría y su éxito predictivo, la mejor explicación del éxito predictivo continuado de las teorías científicas - afirman - es su verdad aproximada. Ahora bien, la fuerza de este argumento descansa en la implausibilidad de las explicaciones alternativas de hechos tan singulares como la predicción de la existencia de fenómenos o de objetos completamente desconocidos y completamente inesperados (la existencia del planeta Neptuno o la curvatura de la luz en campos gravitatorios), o como las coincidencias cuantitativas extremas entre predicciones teóricas y datos obtenidos experimentalmente, que llegan hasta el noveno decimal (el caso del momento magnético del electrón), o como el refuerzo mutuo de teorías independientes (el atomismo en química y la teoría cinética de los gases) (cfr. Diéguez 2001). 
Con respecto a las predicciones realizadas desde el sistema ptolemaico, el realista puede argüir que se trataba de predicciones referidas siempre al mismo tipo de fenómenos, no de auténticas predicciones novedosas, y que tal éxito predictivo se debía a la posibilidad de ir haciendo un encaje cada vez más fino entre los hechos conocidos y el sistema de epiciclos, dado que con éste es posible generar una enorme variedad de trayectorias posibles. Lo que el sistema ptolemaico no podía hacer era predecir con éxito un fenómeno completamente desconocido, cosa que sí pudo hacer la mecánica newtoniana o la mecánica relativista.

Resulta dudoso, sin embargo, que este argumento de la mejor explicación tenga la misma fuerza cuando se aplica al éxito predictivo que se suele alcanzar fuera de la ciencia, en el entorno cotidiano en el que se movían nuestros ancestros. En tales circunstancias, en las que las predicciones, por muy exactas que fueran, no pasarían de la precisión alcanzable sin medios tecnológicos, las explicaciones alternativas a la realista no resultan tan implausibles como en el caso anterior. El instrumentalismo, el idealismo epistemológico o el fenomenismo, pongamos por caso, no tendrían demasiados problemas para explicar, sin recurrir a la idea de un conocimiento verdadero sobre una realidad independiente, por qué los seres humanos son capaces de predecir la trayectoria de una presa en su huida o de un depredador que corre tras ellos. Se trata, en efecto, de posiciones epistemológicas que tradicionalmente han venido haciendo eso: explicar por qué podemos seguir hablando de conocimientos fiables aun cuando rechacemos la idea de un acceso directo a una realidad independiente. Incluso si se concediera que tales casos sólo son explicables presuponiendo un conocimiento verdadero sobre los fenómenos observables, podría negarse todavía que eso implicara un conocimiento verdadero sobre los mecanismos subyacentes y la estructura de una realidad independiente del sujeto. Dicho de otro modo, basta con suponer que nuestras creencias en estos casos son empíricamente adecuadas. 


\section{Conclusiones}

La epistemología evolucionista de los mecanismos cognitivos no puede proporcionar por el momento argumentos suficientemente poderosos en favor del realismo, al menos en sus modalidades más relevantes en el debate epistemológico actual. Una cosa es mostrar que nuestras capacidades cognitivas existen porque aumentan nuestra eficacia biológica, y otra muy distinta mostrar que aumentan nuestra eficacia biológica porque ofrecen un conocimiento que se corresponde con el modo en que la realidad es en sí misma. Cabe poner en tela de juicio que sea necesario postular un conocimiento de este tipo para explicar el valor adaptativo de nuestras capacidades cognitivas. En efecto, la utilidad de éstas para aumentar nuestra eficacia biológica es compatible con la posesión de representaciones ampliamente distorsionadas, y en ocasiones claramente erróneas, de la realidad.

Quizás sea mucho decir, con Nietzsche y con algunos antirrealistas actuales, que lo realmente útil para la vida no son las verdades, sino ciertas ficciones reguladoras, ciertas ilusiones y errores. No obstante, si consideramos que la selección natural es una fuerza "satisfacedora" más que "optimizadora", el resultado serán capacidades cognitivas suficientemente buenas en su valor adaptativo. A tal efecto, un conocimiento empíricamente adecuado es todo lo que se necesita, aun cuando las creencias teóricas sobre las que se sustente dicho conocimiento sean falsas. Para sobrevivir y reproducirse basta con percibir un espacio tridimensional, no hace falta representarse uno tetradimensional.

Por otra parte, la estrategia que el realista emplea en relación con el éxito predictivo de la ciencia, es decir, el recurso a la verdad aproximada como mejor explicación de dicho éxito, pierde mucha de su fuerza cuando se aplica al conocimiento ordinario. La fiabilidad de nuestras percepciones, pongamos por caso, es explicable de forma igualmente satisfactoria desde posiciones realistas y antirrealistas. 


\section{BIBLIOGRAFÍA}

Boyd, R. y J.B. Silk, 2000, How Humans Evolved, Norton, Nueva York.

Bradie, M., 1986, "Assessing Evolutionary Epistemology", Biology and Philosophy, vol. 1, pp. 401-459.

—_, 1990, "Should Epistemologist Take Darwin Seriously?", en N. Rescher (comp.), Evolution, Cognition, and Realism, pp. 33-38.

Callebaut, W., 1993, Taking the Naturalistic Turn, The University of Chicago Press, Chicago.

Calvin, W.H., 1996, How Brains Think, Phoenix, Londres.

Campbell, D.T., 1974, "Evolutionary Epistemology", en P. Schilpp (comp.), The Philosophy of Karl Popper. The Library of Living Philosophers, vol. 14, Open Court, LaSalle, Ill., pp. 413-463.

Castrodeza, C., 1998, "Naturalismo biológico", en P. Martínez-Freire (comp.), Filosofía actual de la ciencia, suplemento 3 de Contrastes, Universidad de Málaga, Málaga.

—_ 1999, Razón biológica. La base evolucionista del pensamiento, Minerva Ediciones, Madrid.

Clark, A.J., 1984, "Evolutionary Epistemology and Ontological Realism", The Philosophical Quarterly, 137, pp. 482-490.

Cummins, D.D., 2000, "How the Social Environment Shaped the Evolution of Mind", Synthese, 122, pp. 3-28.

Dawkins, R., 1999, The Extended Phenotype, Oxford University Press, Oxford.

Diéguez, A., 1998, Realismo científico, Universidad de Málaga, Málaga.

, 2001, "Las explicaciones del éxito de la ciencia. Un análisis comparativo", en P. Martínez-Freire, J. Vicente Arregui, D. Mantero y P. Ginés (comps.), Universalismos, relativismos, pluralismos, número monográfico de Themata, no. 27, pp. 15-29.

Goldman, A.H., 1990, "Natural Selection, Justification, and Inference to the Best Explanation", en N. Rescher (comp.), Evolution, Cognition, and Realism, pp. 39-46.

Hooker, C.A., 1987, A Realistic Theory of Science, State University of New York Press, Albany, N.Y.

- 1995, Reason, Regulation, and Realism, State University of New York Press, Albany, N.Y.

Kant, I., 1787/1966, Kritik der Reinen Vernunft, Reclam, Stuttgart. 
Laudan, L., 1996, "A Confutation on Convergent Realism", en D. Papineau (comp.), The Philosophy of Science, Oxford University Press, Oxford, pp. 107-138.

Lewontin, R.C. 1982, "Organism and Environment", en H.C. Plotkin (comp.), Learning, Development, and Culture, pp. 151170.

Lorenz, K., 1941/1982, “Kant's Doctrine of the a priori in the Light of Contemporary Biology", en H.C. Plotkin (comp.), Learning, Development, and Culture, pp. 121-143.

—_ 1973, Die Rückseite des Spiegels, Piper, Munich.

Lütterfelds, W., 1999, "Una crítica trascendental a la teoría evolucionista del conocimiento", en E. García y J. Muñoz (comps.), La teoría evolucionista del conocimiento, Editorial Complutense, Madrid, pp. 113-130.

Martin, R.D., 2000, "Capacidad cerebral y evolución humana", en AA.VV. Los orígenes de la humanidad, número especial de Investigación y ciencia, Temas 19, pp. 5-61.

McLean, A., 2001, "Cognitive Abilities. The Result of Selective Pressures on Food Adquisition?", Applied Animal Behaviour Science, vol. 71, no. 3, pp. 241-258.

Meyers, R.G., 1990, "Evolution as a Ground for Realism", en N. Rescher (comp.), Evolution, Cognition and Realism, pp. 111118.

Millikan, R., 1984, Language, Thought, and other Biological Categories, The MIT Press, Cambridge, Mass.

Mithen, S., 1996, The Prehistory of the Mind, Thames and Hudson, Londres.

Monod, J., 1970/1981, El azar y la necesidad, trad. F. Ferrer Lerín, Tusquets, Barcelona.

Nagel, T., 1986, The View from Nowhere, Oxford University Press, Nueva York.

Niiniluoto, I., 1984, Is Science Progressive?, Reidel, Dordrecht. Oxford. 1999, Critical Scientific Realism, Oxford University Press,

Pacho, J., 1995, ¿Naturalizar la razón? Alcance y límites del Naturalismo Evolucionista, Siglo Ventiuno, Madrid.

Pinker, S., 1997, How the Mind Works, Norton, Oxford.

Plotkin, H.C. (comp.), 1982, Learning, Development, and Culture, John Wiley \& Sons, Chichester. 
Popper, K.R., 1990, "Towards an Evolutionary Theory of Knowledge", A World of Propensities, Thoemmes, Bristol, pp. 27-51.

Putnam, H., 1983, "Why Reason Can't Be Naturalized", Realism and Reason. Philosophical Papers, vol. 3, Cambridge University Press, Cambridge.

—_ 1992, Renewing Philosophy, Harvard University Press, Cambridge, Mass.

Quine, W.V.O., 1969/1997, "Natural Kinds", en H. Kornblith (comp.), Naturalizing Epistemology, The MIT Press, Cambridge, Mass., pp. 57-75. (Publicado originalmente en Quine, Ontological Relativity and Other Essays, Columbia University Press, Nueva York, 1969.)

Rescher, N. (comp.), 1990, Evolution, Cognition and Realism, University Press of America, Lanham.

Rorty, R., 1998, Truth and Progress. Philosophical Papers, vol. 3, Cambridge University Press, Cambridge.

Rogers, L.J., 1997, Minds of Their Own, Allen and Unwin, St. Leonard.

Ruse, M., 1986, Taking Darwin Seriously, Blackwell, Oxford. , 1990, “Does Evolutionary Epistemology Imply Realism?”, en N. Rescher (comp.), Evolution, Cognition and Realism, pp. 101110.

Sjölander, S., 1997, “On Evolution of Reality. Some Biological Prerequisites and Evolutionary Stages", Journal of Theoretical Biology, vol. 187, no. 4, pp. 595-600.

Skagestad, P., 1981, "Hipothetical Realism", en M.B. Brewer y B.E. Collins (comps.), Scientific Inquiry and the Social Sciences. A Volume in Honor of Donald T. Campbell, Jossey-Bass Publishers, San Francisco.

Stein, E., 1990, "Getting Closer to the Truth: Realism and the Metaphysical and Epistemological Ramifications of Evolutionary Epistemology", en N. Rescher (comp.), Evolution, Cognition and Realism, pp. 119-129.

—_, 1996, Without Good Reason, Clarendon Press, Oxford.

Stich, S.P., 1990, The Fragmentation of Reason, The MIT Press, Cambridge, Mass.

—, 1994 , "Could Man Be an Irrational Animal?", en H. Kornblith (comp.), Naturalizing Epistemology, The MIT Press, Cambridge, Mass., pp. 337-357. 
Vollmer, G., 1987, "What Evolutionary Epistemology Is Not", en W. Callebaut y R. Pinxten (comps.), Evolutionary Epistemology. A Multiparadigm Program, Reidel, Dordrecht, pp. 203-221.

Wilson, D.S., 1990, "Species of Thought: A Comment on Evolutionary Epistemology", en Biology and Philosophy, vol. 5, pp. 37-62.

Woolgar, S., 1998, Science: The Very Idea, Tavistock, Londres.

Recibido el 24 de julio de 2002; aceptado el 2 de octubre de 2002 